\title{
ASTRONOMIA CULTURAL: ANÁLISE DE MATERIAIS E CAMINHOS PARA A DIVERSIDADE NAS AULAS DE CIÊNCIAS DA NATUREZA
}

\author{
MARTA DE SOUZA RODRIGUES ${ }^{\text {** }}$ \\ https://orcid.org/0000-0003-2036-4090 \\ CRISTINA LEITE ${ }^{\prime * *}$ \\ https://orcid.org/0000-0001-8177-4603
}

RESUMO: A astronomia cultural estuda a produção de saberes sobre o céu atrelada às manifestações socioculturais dos povos, possuindo a potencialidade de abordar a diversidade cultural no contexto das aulas de ciências da natureza. Este trabalho, de natureza teórica, consiste em uma análise de doze materiais e propostas didáticas que abordaram a astronomia cultural, e investigou dois principais aspectos: os temas de maior recorrência e as abordagens ao multiculturalismo. Os resultados indicaram a maior recorrência de narrativas sobre o funcionamento do universo e os asterismos de algumas etnias indígenas, além de narrativas sobre entes celestes, a construção de calendários, entre outros. Da abordagem ao multiculturalismo, identificou-se uma polarização entre um viés diferencialista, que valoriza as diferenças culturais dos grupos, e uma postura intercultural, com ênfase no diálogo entre variadas culturas.

Palavras-chave: Ensino de ciências da natureza. Astronomia cultural. Multiculturalismo. Análise de materiais didáticos.

\section{ASTRONOMÍA CULTURAL: ANÁLISIS DE MATERIALES Y CAMINOS A LA DIVERSIDAD EN CLASES DE CIENCIAS DE LA NATURALEZA}

RESUMEN: La astronomía cultural estudia la producción de conocimientos sobre el cielo conjuntamente con las manifestaciones socioculturales de los pueblos, y tiene el potencial de abordar la diversidad cultural en las clases de ciencias naturales. Este trabajo, de carácter teórico, consiste en un análisis de doce materiales y propuestas didácticas que abordaron la astronomía

\footnotetext{
* Mestra em Ensino de Ciências pela Universidade de São Paulo (USP). Doutoranda do Programa Interunidades em Ensino de Ciências da Universidade de São Paulo (PIEC/USP). E-mail:<martasouza@usp.br>.

* *Doutora em Educação pela Universidade de São Paulo (USP). Professora do Instituto de Física da Universidade de São Paulo (USP). E-mail:<crismilk@if.usp.br >.
}

' Universidade de São Paulo, Programa Interunidades em Ensino de Ciências, São Paulo, SP - Brasil.

" Universidade de São Paulo, Instituto de Física, São Paulo, SP - Brasil. 
cultural, e investigó dos aspectos principales: los temas más recurrentes y los enfoques del multiculturalismo. Los resultados indicaron la mayor recurrencia de narraciones sobre el funcionamiento del universo y los asterismos de algunas etnias indígenas, además de narraciones sobre seres celestiales, la construcción de calendarios, entre otros. Desde el enfoque del multiculturalismo, se identificó una polarización entre un sesgo diferencialista, que valora las diferencias culturales de los grupos, y una postura intercultural, con énfasis en el diálogo entre diferentes culturas.

Palabras clave: Enseñanza de ciencias naturales. Astronomía cultural. Multiculturalismo. Análisis de materiales didácticos.

\section{CULTURE ASTRONOMY: ANALYSIS OF MATERIALS AND PATHS TO DIVERSITY IN NATURE SCIENCE CLASSES}

ABSTRACT: Cultural astronomy studies the production of knowledge about the sky linked to the sociocultural manifestations of peoples, having the potential to address cultural diversity in the context of nature science classes. This theoretical research consists of an analysis of twelve materials and teaching proposals that approached cultural astronomy and investigated two main aspects: the most recurrent themes and approaches to multiculturalism. The results indicated the greatest recurrence of narratives about the functioning of the universe and the asterisms of some indigenous ethnic groups, as well as narratives about celestial beings, the construction of calendars, among others. From the approach to multiculturalism, a polarization was identified between a differentialist bias, which values the cultural differences of the groups, and an intercultural stance, with emphasis on the dialogue between different cultures.

Keywords: Natural sciences education. Cultural astronomy. Multiculturalism. Analysis of didactic materials. 


\section{INTRODUĈ̣̃O}

Muitos são os temas ou discussões contemporâneas que se mostram desafiadoras à escola neste início de século. Em um cenário amplo, elas se conectam e se desdobram em variados fatores, envolvendo processos complexos. Tomando como base a globalização, um de seus fenômenos decorrentes é a aproximação e o contato entre diferentes povos e culturas, produzindo não apenas um rearranjo entre diferentes filosofias, se estendendo além do racionalismo europeu, como originando uma "sociodiversidade" (SANTOS, 2001, p. 20). Alguns dos possíveis desdobramentos dessa nova configuração mundial se relacionam ao reconhecimento da diversidade cultural entre os povos, assim como a necessidade de promover ações que garantam visibilidade e espaço de atuação a grupos que, historicamente, foram silenciados das grandes narrativas.

Comisso, deu-se origem a condições que permitiram a emergência de debates a respeito da criação de espaços de valorização de saberes e práticas produzidas por diferentes culturas. Um marco internacional nesse sentido consiste na "Declaração Universal sobre a Diversidade Cultural” (UNESCO, 2001), documento em que a diversidade cultural é tomada como patrimônio da humanidade e parte dos direitos humanos. Em se tratando da educação, a Declaração menciona em seu plano de ação: "6. Fomentar, por meio da educação, uma tomada de consciência do valor positivo da diversidade cultural e aperfeiçoar, com esse fim, tanto a formulação dos programas escolares como a formação dos docentes." (UNESCO, 2001, p.6).

Dentre as propostas teóricas que surgiram para compreender esta nova configuração planetária, encontra-se o multiculturalismo, que pode ser pensando inicialmente como um conjunto de estratégias e normas a possibilitarem a coexistência de variadas culturas em um dado espaço, sem que haja a sobreposição de uma delas sobre as demais (BINJA, 2015). Inglis (1996) destaca que, devido à complexidade do fenômeno do multiculturalismo, três distinções podem ser feitas a partir de alguns contextos: demográfico-descritivo, relacionado a existência de diversas etnias ou culturas em uma sociedade; programático-político, que se concretiza na criação de políticas para lidar com a diversidade étnica e racial; ideológica-normativa, fundamentada na necessidade de garantir aos indivíduos oriundos de culturas nãodominantes o acesso aos princípios e bens compartilhados em sociedade.

Outra proposta para a compreensão mais aprofundada desta discussão provém de Candau (2008), em que a autora apresenta três diferentes tipos de multiculturalismo: assimilacionista, diferencialista (ou monoculturalismo plural) e interativo (ou interculturalidade).

Das definições construídas por Candau, o multiculturalismo assimilacionista reconhece o caráter plural e diversificado da sociedade, buscando incorporar à cultura dominante os grupos que se encontram em desvantagem ou à margem, devido a algum aspecto particular. Não há um questionamento acerca da posição privilegiada conferida a uma única cultura em caráter hegemônico. Já na abordagem diferencialista, é dada ênfase às características consideradas específicas de alguns grupos de acordo com suas raízes culturais e ancestralidades. Neste caso, não se defende a integração e assimilação em massa à cultura dominante. Ao contrário, 
o multiculturalismo diferencialista busca a criação de espaços em que os grupos possam usufruir de liberdade para a realização de suas vivências. Candau (2008) faz a ressalva de que esta abordagem apresenta, de forma implícita, um caráter essencialista e estático para a ideia de cultura e a formação das identidades culturais.

Por fim, o multiculturalismo interativo (ou interculturalidade, como será usado de forma predominante no trabalho) prioriza a ideia de diálogo e intercâmbio cultural com o objetivo de construir o pluralismo, a democracia, a articulação entre políticas de inclusão e de identidade nas sociedades contemporâneas. São apontadas por Candau cinco principais características ligadas à interculturalidade: a relação de intercâmbio entre diferentes culturas, sendo este um ponto de oposição direta às duas abordagens anteriores; a concepção de dinamismo intrínseco às culturas, que estariam em constante transformação; a negação da existência de culturas que poderiam ser chamadas de "puras", prevalecendo os processos de hibridização cultural; a consciência acerca das relações de poder e dominação que permeiam a história dos povos, refletidas na existência de uma cultura tomada como superior ou aquela a ser reproduzida; a abordagem a questões relativas à diferença e à desigualdade, buscando diferenciar cada uma das noções.

No Brasil, em termos dos documentos que fornecem orientações à produção de currículos no território nacional, identifica-se um histórico de ações que promovem o trabalho com temas transversais na educação básica como um todo e que envolvem a questão da diversidade cultural. É o caso do Tema Transversal da Pluralidade Cultural presente nos Parâmetros Curriculares Nacionais (PCN), ressaltando-se que os PCN se configuram enquanto recomendações para a educação básica criadas na segunda metade da década de 1990, não possuindo caráter obrigatório a implementação de suas orientações gerais. Ao longo da década seguinte, ganhou relevância na escola a discussão a respeito de temas voltados à promoção da cidadania e a questões sociais.

No âmbito da diversidade e do reconhecimento do Brasil enquanto um território multicultural, um marco legal nesse sentido diz respeito à aprovação da Lei $n^{\circ}$ 10.639/03, que alterou a Lei n ${ }^{\circ}$ 9.394/96 de modo a tornar obrigatório em todo o currículo escolar, de forma transversal, o estudo da História da África e dos africanos, além de aspectos da cultura negra na formação do Brasil. Em 2008, a aprovação da Lei no 11.645/08 incorporou os povos indígenas no Brasil às determinações existentes com a Lei no 10.639/03, tornando também obrigatória a abordagem a história e cultura de tais populações.

Com a homologação da Base Nacional Comum Curricular (BNCC), tal contexto ganhou um novo componente. Os Temas Transversais, indicados nos PCN, surgem na BNCC como Temas Contemporâneos Transversais (TCTs) de forma expandida, englobando 15 temas organizados em seis grandes áreas (BRASIL, 2019). Em "Multiculturalismo", estão presentes os temas: "Diversidade Cultural" e "Educação para valorização do multiculturalismo nas matrizes históricas e culturas brasileiras".

Duas características marcantes podem ser indicadas nesse movimento recente de destaque à diversidade cultural nos documentos que orientam a criação dos currículos na educação básica: a obrigatoriedade da abordagem a tais questões, 
dado o caráter normativo da BNCC, apoiando-se na aprovação durante a última década de duas leis federais relacionadas a essa temática; a transversalidade como forma de abordagem, tendo em vista a proposta dos TCTs, que inserem na discussão todas as áreas do conhecimento ou disciplinas do currículo.

Diante das demandas e determinações apresentadas anteriormente, decorrentes de reivindicações de movimentos sociais ao longo de décadas, tornamse necessários os questionamentos a seguir: quais áreas de pesquisa ou grandes temas podem favorecer o trabalho com a diversidade cultural nas aulas de ciências da natureza? Quais assuntos têm sido abordados por materiais e propostas didáticas nesse contexto? Quais visões tais materiais apresentam a respeito de questões mais amplas, envolvendo perspectivas voltadas ao multiculturalismo? Quais caminhos podem ser indicados para levar as disciplinas de ciências da natureza a discutirem aspectos da diversidade cultural em sala de aula?

Este trabalho tem o objetivo de apresentar uma síntese acerca de tais questionamentos gerais ${ }^{1}$. Ao longo de seu encaminhamento, discute-se o potencial da astronomia cultural para trabalhar com a temática da diversidade cultural, tendo em vista sua abordagem à construção do conhecimento sobre o céu na perspectiva de diferentes povos. Em um segundo momento, serão apresentados os principais resultados de uma análise envolvendo materiais e propostas didáticas com tópicos de astronomia cultural. A partir dos resultados obtidos, serão indicados eixos ou linhas de atuação que podem orientar a criação de novas propostas e materiais voltados a sala de aula, fomentando práticas que trabalhem com a diversidade na construção do conhecimento nas ciências da natureza.

\section{A ASTRONOMIA CULTURAL E A PRODUÇ̃̃O DA ÁREA NAS ÚLTIMAS DÉCADAS}

A astronomia cultural pode ser compreendida como a área do conhecimento em que os saberes acerca dos elementos celestes são estudados de maneira integrada às manifestações socioculturais de um dado povo ou grupo. Em outras palavras: "a astronomia cultural se refere aos saberes, práticas e teorias elaboradas por qualquer sociedade, ou cultura, a respeito das relações céu-terra e o que disso decorre nas dinâmicas culturais e representações sobre o mundo" (LIMA et al., 2013, p. 100).

Nesta perspectiva, é importante considerar que o termo "astronomia" deve ser compreendido em um contexto mais amplo do que o habitualmente delimitado pelo meio acadêmico, podendo ser aproximado da ideia de "saberes sobre as coisas do céu” (JAFELICE, 2009). Logo, fenômenos considerados meteorológicos, atmosféricos, cosmológicos e climáticos, na perspectiva da academia, podem ser incorporados à astronomia cultural. A referência ao "cultural" indica a relevância de serem considerados os aspectos socioculturais e contextuais atrelados à construção dos conhecimentos sobre o céu.

Em se tratando de possíveis discussões promovidas nesta área, um dos exemplos considerados mais antigos para ilustrar a interação da humanidade com os elementos celestes, de maneira conectada a aspectos socioculturais e econômicos, consiste na construção de calendários. A regularidade dos movimentos dos astros desde cedo foi aproveitada como instrumento de medição 
temporal. Tal aspecto permitiu a criação de calendários que organizavam a vida social com a indicação de rituais e festividades, servindo de orientação para os períodos mais adequados a plantios e colheitas, fator este importantíssimo para o surgimento dos primeiros grupos sedentários. Os calendários de povos que habitaram a região da antiga Mesopotâmia, por exemplo, baseavam-se na observação dos ciclos lunares, com 29 ou 30 dias, resultando em um ano de 354 dias (GRECO, 2006). Além disso, os sacerdotes que detinham conhecimentos sobre o céu à época desempenhavam papel de destaque na sociedade.

Os Kayapó, povo indígena que ocupa territórios nos estados do Mato Grosso e Pará no Brasil, possuem um complexo sistema de observação dos fenômenos terrestre e celestes, que se relaciona ao conjunto de saberes que integram o ambiente em que vivem. Campos (2006) apresenta diversos elementos da cosmologia dos Kayapó a partir de suas pesquisas na aldeia Gorotire, no estado do Pará. Entre os aspectos apontados pelo pesquisador, encontram-se elementos de natureza simbólica, como o lugar e papel dos "Waiangá" (correspondendo às figuras de xamãs ou pajés), o sistema de orientação para as direções cardeais, entre outros. Sobre esse último ponto, Campos (2006) apresenta a forma de orientação corporal Kayapó a partir do movimento nascente-poente do Sol: ao se colocarem deitados, com as costas apoiadas sobre o solo, os pés devem apontar para o nascente ("início do céu”) e a cabeça, para o poente ("fim do céu”); a posição do umbigo corresponderia ao centro da aldeia, de maneira que sua projeção para cima indica o "alto do céu”. Comparando o sistema de orientação espacial Kayapó ao ensinado tradicionalmente em livros didáticos e nas escolas regulares:

Nelas ensina-se a apontar a mão direita para o nascente. Isso, consequentemente, nos
coloca de frente para o norte e aparentemente para a Estrela Polar. [...] Desse modo
somos ensinados a ficar de frente para algo que não vemos e acabamos dando as
costas para o que vemos: a constelação do Cruzeiro do Sul. Esta sim é o recurso de
orientação noturna mais visível no Hemisfério Sul. Nesse caso a regra definitivamente
prática seria ensinarmos a colocar a mão esquerda em direção à nascente. Desse modo,
à noite estaríamos de frente para o Cruzeiro do Sul e olhando na direção sul. Em vez
de NORTEar, a proposta aqui é SULear. (CAMPOS, 2006, p. 66)

No exemplo da orientação espacial dos Kayapó, ressalta-se a lógica que orienta tal prática e o quanto este tipo de saber está voltado para uma observação atenta da natureza. Destaca-se ainda que a cultura promove significados específicos, usos e aplicações próprias ao conhecimento sobre o céu. Logo, a astronomia, enquanto produto da tradição ocidental, passa a ser pensada nesta perspectiva como uma forma válida e relevante, entre outras, de se organizar e dar sentido aos conhecimentos acerca do céu.

Considerando o contexto internacional e a publicação de periódicos de acesso aberto e de relevância na área de estudos culturais vinculados à educação, como é o caso do International Journal of Multicultural Education (IJME), realizou-se um levantamento bibliográfico no período de 2010 a 2019, a fim de identificar pesquisas vinculadas às discussões gerais abordadas neste artigo ${ }^{2}$. As temáticas centrais de maior 
recorrência no periódico trataram sobre: a aprendizagem de línguas, ou a educação bilingue, em variados contextos; questões relacionadas a raça, racismo e negritude; a situação dos imigrantes e os fluxos migratórios; estudos a respeito da cultura de grupos étnicos específicos. Em se tratando das publicações sobre temas de interesse deste artigo, destaca-se que nove artigos, no total de 179 publicados no período considerado, abordaram a valorização dos conhecimentos de povos originários no currículo e/ou no contexto de uma implementação de educação intercultural.

Das publicações a respeito da inserção de conhecimentos e saberes oriundos de variadas matrizes culturais, questionando a lógica monocultural dos currículos de escolas não indígenas, Carjuzaa (2012) abordou a lei conhecida como Educação Indígena para Todos (Indian Education of All - IEA) em Montana, Estados Unidos, e as dificuldades em implementá-la, tendo em vista a formação dos professores, carente de elementos que permitiriam a promoção de uma educação intercultural. Neste contexto, McCarthy e Stanton (2017) apresentaram experiências a respeito da inclusão de contranarrativas pautadas nos conhecimentos dos povos indígenas, apoiando-se no programa IEA. Jacob et al. (2018) também promoveram a defesa dos conhecimentos indígenas no currículo escolar pautando-se na legislação. Neste caso, trata-se do Projeto de Lei do Senado de Oregon, Estados Unidos: "Senate Bill 13: Tribal History/Shared History", que apoia o desenvolvimento e implementação de um currículo que contemple a história dos povos nativos da região.

A partir do levantamento bibliográfico no IJME, foi identificado um único trabalho em que os conhecimentos e saberes de culturas não ocidentais foram abordados no contexto do ensino de ciências. Boutte, Kelly-Jackson e Johnson (2010) realizaram a pesquisa no contexto estadunidense, objetivando apresentar exemplos de práticas, nas aulas de ciências, fundamentadas no referencial da pedagogia culturalmente relevante ("Culturally relevant pedagogy"), a fim promover a abordagem ao conhecimento científico, compreendendo e respeitando os saberes de culturas não ocidentais. $\mathrm{O}$ artigo enfatiza a necessidade de incluir nos currículos as vozes e visões de mundo que foram silenciadas, realizando um "duplo movimento": o reconhecimento e compreensão de saberes tradicionais de culturas não ocidentais e a busca por dar maior significado aos conceitos científicos ocidentais. Como síntese dos resultados mais relevantes do levantamento, ressaltase a referência recorrente às leis como motores para impulsionar as mudanças nos currículos, além da escassez de trabalhos que conectam os estudos culturais ao ensino de ciências. Embora não tenha sido identificado na revisão bibliográfica, vale ressaltar a produção do pesquisador canadense Glen S. Aikenhead (2007), ao construir propostas de conexão entre os conhecimentos tradicionais indígenas e a ciência ocidental nas aulas de ciências.

No que diz respeito à produção brasileira no campo da astronomia cultural, Lima e Figueirôa (2010) apresentam um levantamento de publicações relevantes para a área desde a década de 1990. A década seguinte, indicam as autoras, apresentou uma produção mais sistemática e numerosa, incluindo a realização de congressos internacionais em áreas como a antropologia, história das ciências, arqueologia, entre outras, que se converteram em contribuições 
à astronomia cultural. Em se tratando das publicações voltadas ao ensino de ciências e astronomia, levantamentos bibliográficos foram realizados a fim de criar panoramas sobre o estado da arte em astronomia cultural. É o caso de Albuquerque et al. (2011), que partiu das publicações realizadas por periódicos nacionais e internacionais, bancos de teses e dissertações, assim como trabalhos completos publicados nas atas de três eventos da área de ensino de física, durante o período de 2000 a 2010 . Ao todo, foram consultadas as edições publicadas por 21 revistas, somando cerca de 4800 artigos. Em relação aos documentos publicados em atas de eventos, a estimativa das autoras é de que tenham sido consultados cerca de 4500 trabalhos. Deste universo, foram identificados apenas quatro trabalhos ligados à astronomia cultural. Ampliando-se a base de busca, foram consultados bancos de teses e dissertações, entre outras plataformas, chegando, ao fim, a um corpus de análise composto por 11 trabalhos. Albuquerque et al. (2011) propuseram a criação de duas grandes categorias de análise neste contexto: "Reconhecimento cultural" e "Propostas de ensino". O primeiro agrupamento reuniu quatro trabalhos com o objetivo principal de divulgar os saberes sobre o céu elaborados por diferentes grupos e culturas. Para isso, os artigos apresentaram relatos de pesquisas de campo ou pesquisas em fontes etnográficas. Já em "Propostas de ensino", foram identificados trabalhos destinados a: educação formal, estruturados a partir de elementos interdisciplinares ou holísticos; educação não-formal, com propostas a serem realizadas com públicos de faixa etária variável e em espaços como planetários.

Dando continuidade ao estado da arte anterior, Merlucci, Killner e Oliveira Júnior (2019) realizaram um levantamento bibliográfico, no período de 2010 a 2018, recorrendo às atas dos mesmos eventos consultados por Albuquerque et al. (2011), além de 14 periódicos da área de ensino. A estimativa dos autores indica o contato com cerca de 4500 artigos, dos quais 12 abordaram temáticas da astronomia cultural. Também foram consultados bancos de teses e dissertações, de maneira que, ao final, os autores identificaram para o corpus da análise um total de 17 novos trabalhos abordando a astronomia cultural no contexto do ensino de ciências e física. Merlucci, Killner e Oliveira Júnior (2019) mantiveram as categorias de análise "Reconhecimento cultural" (quatro documentos) e "Propostas de ensino" (oito documentos, considerando a soma entre os trabalhos destinados à educação formal e não formal), todavia, propuseram um novo agrupamento: "Análise documental". Nesta categoria, concentram-se os trabalhos em que se realiza uma pesquisa documental sobre a área de astronomia cultural em si, envolvendo levantamentos bibliográficos ou a análise de materiais que promoveram abordagens à astronomia cultural. Os autores ainda destacam, como síntese dos dois levantamentos que contemplaram o período de 2000 a 2018, uma concentração das publicações e produção nos últimos quatro anos, podendo ser interpretado como um crescimento recente da temática no ensino de ciências da natureza.

A realização dos levantamentos bibliográficos anteriores cumpre o importante papel de apresentar e organizar a produção existente em suas tendências mais gerais sobre a astronomia cultural. Compreende-se que, como 
uma possibilidade de aprofundamento, é necessário explorar as formas, estruturas e escolhas adotadas pelos materiais e propostas didáticas em suas abordagens ao tema. Nesse sentido, apresenta-se a seguir a análise de um conjunto de materiais no que diz respeito à astronomia cultural.

\subsection{ABORDA GENS À ASTRONOMIA CULTURAL}

O processo de seleção que originou o conjunto de materiais e propostas didáticas analisadas neste trabalho envolveu, de início, a consulta ao levantamento bibliográfico de Albuquerque et al. (2011). Dos trabalhos apontados a partir dessa revisão, foram mantidos no corpus os documentos que se relacionaram a experiências didáticas na educação básica - subgrupo "Educação formal" na categoria "Propostas de ensino". Dois outros trabalhos foram desconsiderados da análise por apresentarem apenas indicativos de suas abordagens a respeito da astronomia cultural, não apresentando maiores elementos que pudessem ser analisados. Deste processo, resultaram assim cinco documentos: Jafelice (2002), Costa (2005), Barros (2004), Cardoso (2007) e Melo, Soares e Kerber (2011). A fim de ampliar o corpus de análise, foram considerados outros tipos de materiais, como é o caso dos livros didáticos, mantendo como elemento comum a abordagem à astronomia cultural e o vínculo com situações didáticas. O processo que levou à seleção de duas coleções didáticas, Kantor et al. (2010) e Pietrocola et al. (2011), encontra-se presente em (RODRIGUES; LEITE, 2012). O trabalho de Côrrea et al. (1999), identificado no levantamento de Albuquerque et al (2011), consiste em uma cartilha/livro didático voltado ao público infantojuvenil e, devido a sua estrutura geral, foi incluído ao corpus junto às coleções didáticas. Por fim, ainda com a intenção de ampliar o corpus de análise, realizou-se um levantamento dos referenciais curriculares estaduais, conforme especificado em Rodrigues e Leite (2015). Deste processo, apenas foram identificados materiais destinados a professores e estudantes ("Cadernos do estudante/professor"), produzidos pela Secretaria de Educação de São Paulo, e que abordaram tópicos de astronomia cultural. Desta forma, o hibridismo dos documentos do corpus de análise é decorrência da escassez de materiais a respeito da temática. Além disso, o processo de seleção considerou documentos produzidos até 2013, de maneira que a análise completa foi concluída no final de 2015. Já Oliveira (2018) realizou uma análise mais recente dos livros didáticos em abordagens à astronomia cultural, aprovados no PNLD 2018.

A tabela 1 identifica os materiais analisados de acordo com alguns agrupamentos. 
Tabela 1. Propostas e materiais didáticos analisados

\begin{tabular}{|c|c|c|}
\hline Documento & Título e autor(a) & $\begin{array}{l}\text { Tipo de } \\
\text { material }\end{array}$ \\
\hline DT1 & $\begin{array}{l}\text { “Etnoastronomia Tembé-Tenetehara como matriz de } \\
\text { abordagem (etno)matemática no ensino fundamental" } \\
\text { (BARROS, 2004). }\end{array}$ & \multirow{3}{*}{$\begin{array}{l}\text { Dissertações e } \\
\text { Teses (DT) }\end{array}$} \\
\hline DT2 & $\begin{array}{l}\text { “O Céu dos Tukano na escola Yurupi: construindo um } \\
\text { calendário dinâmico” (CARDOSO, 2007). }\end{array}$ & \\
\hline DT3 & $\begin{array}{l}\text { "Uma abordagem humanística para o ensino de astronomia } \\
\text { no ensino médio" (COSTA, 2005). }\end{array}$ & \\
\hline P1 & $\begin{array}{l}\text { "Astronomia e educação intercultural: experiências no } \\
\text { ensino de astronomia e ciências em escolas indígenas" } \\
\text { (MELLO; SOARES; KERBER, 2011). }\end{array}$ & $\begin{array}{c}\text { Relatos de } \\
\text { experiências/ } \\
\text { propostas } \\
\text { didáticas } \\
\text { publicadas } \\
\text { em atas de } \\
\text { eventos }(\mathrm{P})\end{array}$ \\
\hline LD1 & $\begin{array}{l}\text { “Física em Contextos: pessoal, social e histórico" } \\
\text { (PIETROCOLA et al., 2011). }\end{array}$ & \multirow{3}{*}{$\begin{array}{c}\text { Livros } \\
\text { didáticos (LD) }\end{array}$} \\
\hline LD2 & $\begin{array}{l}\text { “0 céu dos índios Tembé” (CORRÊA; MAGALHÃES; } \\
\text { MASCARENHAS, 1999) }\end{array}$ & \\
\hline LD3 & “Quanta física” (KANTOR et al., 2010). & \\
\hline & “Caderno do Professor", nos volumes indicados a seguir: & \multirow{5}{*}{$\begin{array}{l}\text { Caderno do } \\
\text { Professor } \\
\text { - proposta } \\
\text { curricular } \\
\text { estadual de } \\
\text { São Paulo (CP) }\end{array}$} \\
\hline CP1 & $\begin{array}{l}5^{\text {a }} \text { série do ensino fundamental - Volume } 4 \text { (SÃO PAULO, } \\
\text { 2009). }\end{array}$ & \\
\hline $\mathrm{CP} 2$ & $\begin{array}{l}6^{\text {a }} \text { série do ensino fundamental - Volume } 1 \text { (SÃO PAULO, } \\
2009 \text { b). }\end{array}$ & \\
\hline $\mathrm{CP} 3$ & $\begin{array}{l}7^{\text {a }} \text { série do ensino fundamental - Volume } 3 \text { (SÃO PAULO, } \\
2009 \mathrm{c} \text { ). }\end{array}$ & \\
\hline $\mathrm{CP} 4$ & $1^{\circ}$ ano do ensino médio - Volume 3 (SÃO PAULO, 2009d). & \\
\hline
\end{tabular}

\subsection{CAMINHOS METODOLÓGICOS PARA A ANÁLISE}

A análise de conteúdo foi a metodologia utilizada no tratamento dos materiais. Neste referencial, é proposta uma articulação entre o que seriam as "superfícies dos textos", suas mensagens mais explícitas, e a sua análise descritiva, 
remetendo-se às variáveis que são inferidas neste processo. Sobre as etapas deste método, Bardin (2006) propõe sua organização em três grandes momentos: a préanálise, a exploração do material e o tratamento dos resultados.

Ressalta-se o fato de que a abordagem predominante na análise é de natureza qualitativa, segundo os elementos gerais propostos por Bogdan e Biklen (1994), tendo em vista fatores como: o trabalho com mensagens e textos, além do reduzido número de documentos do corpus; seu caráter descritivo, como forma de se atingir uma compreensão mais apurada dos objetos estudados; o interesse em compreender os processos e os contextos em que estão inseridos os materiais; a adoção de uma perspectiva indutiva, ao não utilizar os dados para confirmar hipóteses feitas previamente.

Com a leitura dos documentos do corpus ${ }^{3}$, foi possível elaborar duas dimensões de análise, que podem ser compreendidas como temáticas específicas ou eixos de investigação a serem explorados. Em síntese, tais dimensões podem ser apresentadas como sendo: 1. Temas abordados em astronomia cultural; 2. Perspectivas de multiculturalismo e da noção de cultura nos documentos.

Com a investigação de tais eixos, o objetivo é apresentar considerações e apontamentos a respeito de questionamentos, como: qual a recorrência das discussões de astronomia cultural no corpus de análise? Quais assuntos se destacam por possuírem maior frequência? Quais temáticas são pouco exploradas? É possível identificar o tipo de visão adotada pelo corpus em termos de uma educação multicultural? Prevalecem concepções estáticas ou dinâmicas acerca do conceito de cultura?

\subsection{RESULTADOS: IDENTIFICANDO TENDÊNCIAS E RECORRÊNCIAS}

\subsubsection{Temas abordados em astronomia cultural}

Iniciando-se pela dimensão de análise 1 (Temas abordados em astronomia cultural), a tabela 2 a seguir reúne os 12 materiais do corpus de análise e apresenta uma síntese da etapa de unitarização (ou codificação) dos dados. Faz parte deste procedimento a identificação dos índices (termos) que se relacionam à astronomia cultural. 
Tabela 2. Processo de unitarização para dimensão de análise 1

\section{Documento Índices relacionados aos temas abordados pelos documentos}

\begin{tabular}{|c|c|c|}
\hline DT1 & $\begin{array}{l}\text { “criação do mundo"; “Lua”/“ciclo lunar”; “a estrela da } \\
\text { manhã” e “a mulher da Lua”; “Sol e seu movimento } \\
\text { diário"; “estações do ano"; “calendário”; “constelações” } \\
\text { (Ema, Siriema, Duas cruzes, Beija-flor, Canoa, Barquinho, } \\
\text { Anta, Queixo da Anta, Jabuti, Estrelas reunidas). }\end{array}$ & Tembé \\
\hline DT2 & $\begin{array}{l}\text { “siõka” (estrelas ou planetas de brilho destacado); } \\
\text { “constelações do ciclo principal” (Jararaca d’água, Tatu, } \\
\text { Camarão, Onça, Jacundá, Conjunto de estrelas, Armadilha } \\
\text { de pesca, Enxó, Garça); "estrela cadente"; “constelações } \\
\text { marginais" (Jararaca de ânus grande, Cágado); “via } \\
\text { láctea” (mito de criação); “calendário Tukano”. }\end{array}$ & Tukano \\
\hline DT3 & $\begin{array}{l}\text { "constelações"; "origem do universo"; “"cosmologia"; } \\
\text { "pensamento indígena de integração"; "vivência do } \\
\text { simbólico" e "integração do indivíduo ao cosmo". }\end{array}$ & $\begin{array}{c}\text { Tembé, cultura } \\
\text { havaiana, Desana, } \\
\text { Tubuguaçu, Tupi- } \\
\text { guarani. }\end{array}$ \\
\hline $\mathrm{P} 1$ & "pensamento guarani” e "cosmologia". & Guarani \\
\hline $\mathrm{P} 2$ & "mito/representação simbólica"; "vivências". & $\begin{array}{l}\text { Sem menção } \\
\text { a uma cultura } \\
\text { indígena. }\end{array}$ \\
\hline LD1 & $\begin{array}{l}\text { “cosmologias” (egípcia e Kayapó); “calendários” } \\
\text { (babilônico, egípcio, romano, gregoriano e maia). }\end{array}$ & Kayapó \\
\hline LD2 & $\begin{array}{l}\text { "estações do ano"; “Sol”; “Lua”; “Vênus”; “constelações” } \\
\text { (Caminho da cruz, Ema, Siriema, Estrelas reunidas, Queixo } \\
\text { da anta, Anta, Beija-flor, Jabuti, Canoa). }\end{array}$ & Tembé \\
\hline LD3 & “cosmologia” (sumérios, chineses, incas e egípcios). & $\begin{array}{l}\text { Sem menção } \\
\text { a uma cultura } \\
\text { indígena. }\end{array}$ \\
\hline CP1 & $\begin{array}{l}\text { “lendas e mitos indígenas sobre a origem e a forma da } \\
\text { Terra"; "religiões indígenas". }\end{array}$ & Tupi Guarani \\
\hline $\mathrm{CP} 2$ & “constelações”. & Tembé \\
\hline CP3 & $\begin{array}{l}\text { "calendários" lapenas chinês e maia); “significados da Lua } \\
\text { e do Sol (egípcia e guarani)"; “cosmologia" (guarani). }\end{array}$ & Guarani \\
\hline CP4 & “constelações”. & $\begin{array}{l}\text { Sem menção } \\
\text { a uma cultura } \\
\text { indígena. }\end{array}$ \\
\hline
\end{tabular}

A etapa seguinte do processo utilizou os índices (ou unidades) da tabela 2 para construir categorias para a análise. Buscou-se reunir os elementos de acordo 
com as similaridades verificadas, apresentando-se brevemente a ideia geral associada a cada agrupamento resultante da categorização. 1. "Origem do mundo" (OM): discussões voltadas à origem e à criação do universo; 2. "Funcionamento do cosmos" (FC): noção expressa pelos materiais a partir do termo "cosmologia"; 3. "Entes celestes" (EC): abordagem a objetos associados ao céu, como é o caso do Sol, da Lua, de estrelas cadentes ou meteoros, planetas, entre outros; 4. “Estações do ano" (EA): reflexões que relacionam dadas configurações do céu a certos períodos do ano e suas características mais específicas; 5. "Pensamento simbólico e holístico" (PSH): abrange a noção de integração do humano ao cosmos e à natureza a fim de enfatizar a existência de outras lógicas de pensamento, distintas da forma racional e cartesiana do ocidente; 6. "Construção de calendários" (CC): articulação entre a periodicidade dos ciclos dos objetos celestes e a necessidade de organização de eventos sociais, econômicos e religiosos, enfatizando as diferenças dos calendários propostos por diversas culturas; 7 . “Asterismos" (A): padrões no céu reconhecidos a olho nu por diferentes grupos que envolvem um conjunto de significados e simbologias, podendo incluir outros elementos além de agrupamentos de estrelas. Os asterismos podem abarcar uma ou mais regiões do céu identificadas com as 88 constelações oficializadas pela União Astronômica Internacional.

Como síntese e organização geral desta etapa, o quadro 1 identifica as temáticas recorrentes em cada documento, segundo as categorias apresentadas anteriormente.

Quadro 1. Distribuição dos temas abordados pelo corpus de análise

\begin{tabular}{|c|c|c|c|c|c|c|c|c|}
\hline Documento & $O M$ & FC & EC & EA & PSH & CC & A & $\begin{array}{l}\text { Total por } \\
\text { documento }\end{array}$ \\
\hline DT1 & & & & & & & & 5 \\
\hline DT2 & & & & & & & & 3 \\
\hline DT3 & & & & & & & & 4 \\
\hline P1 & & & & & & & & 2 \\
\hline P2 & & & & & & & & 1 \\
\hline LD1 & & & & & & & & 2 \\
\hline LD2 & & & & & & & & 3 \\
\hline LD3 & & & & & & & & 1 \\
\hline CP1 & & & & & & & & 2 \\
\hline $\mathrm{CP} 2$ & & & & & & & & 1 \\
\hline $\mathrm{CP} 3$ & & & & & & & & 3 \\
\hline $\mathrm{CP} 4$ & & & & & & & & 1 \\
\hline $\begin{array}{l}\text { Total por } \\
\text { categoria }\end{array}$ & 3 & 6 & 4 & 2 & 3 & 4 & 6 & \\
\hline
\end{tabular}


$\mathrm{O}$ quadro 1 permite visualizar que duas categorias se destacaram em termos de maior incidência: "Funcionamento do cosmos" (FC) e "Asterismos" (A). Como um aspecto geral dos dados, chama-se atenção para o fato do corpus possuir características, objetivos e extensões diferentes entre si, pontuando-se ainda que a análise não dimensiona a profundidade com a qual os temas foram tratados. O material DT2, por exemplo, aborda o mesmo número de temas que $\mathrm{CP} 3$ e tais trabalhos possuem naturezas bastante distintas, havendo no primeiro deles um grande aprofundamento dos assuntos abordados que não se verifica em CP3.

A categoria "Pensamento simbólico e holístico" (PSH) discute a existência de outros olhares voltados à compreensão da realidade, distinguindo-se do pensamento racionalista predominante no ocidente. Este agrupamento não concentrou um número grande de documentos (3) e as discussões nele realizadas possuem maior complexidade, devido à necessidade de se questionar noções que, ao longo do tempo, tornam-se naturalizadas. É o caso da supervalorização da racionalidade cartesiana e da noção de progresso associada ao desenvolvimento da tecnologia, em detrimento de lógicas de pensamentos que se organizam a partir de outras estruturas. Exige-se, em termos de formação, maior interface com as áreas humanas para a promoção de discussões dessa natureza. Ainda assim, os materiais que representam este agrupamento (DT3, P1 e P2) apontaram possíveis caminhos para o trabalho nessa perspectiva.

Em "Construção de calendários" (CC), verificou-se a predominância de uma abordagem mais descritiva sobre a temática. Em LD1 e CP3 há comentários gerais sobre os calendários de algumas culturas, como: maia, egípcia, babilônica, incluindo os modelos que estão na origem do calendário utilizado nos dias de hoje na cultura ocidental. No caso de DT1, a abordagem sobre o tema se relaciona a aspectos do calendário Tembé e tem vínculo direto com a temática das estações do ano. A Lua (Zahy) é apontada como referência para a duração dos meses. Já DT2 consiste na exceção às abordagens mais descritivas, dado seu objetivo de construir um calendário junto à comunidade Tukano, articulado a diversos indicadores e fenômenos naturais. Como síntese das características desta categoria, chama-se atenção para os elementos pertencentes ao grupo das dissertações e teses, que optaram por discutir apenas um calendário de matriz indígena. Os materiais direcionados à sala de aula, livro didático (DL1) e material da proposta curricular (CP3), fizeram panoramas mais amplos sobre a temática, não necessariamente enfatizando a relação entre os calendários e as dinâmicas celestes a partir do olhar de variadas culturas.

Os documentos que abordaram o tema das constelações ou "Asterismos" (A) deram ênfase, no geral, a descrições de certas regiões do céu, buscando comparála com as estrelas e constelações definidas pela União Astronômica Internacional (UAI) para identificar os asterismos de uma etnia ou grupo. Em alguns casos, os materiais apresentam motivos que justificariam a existência e denominação de alguns asterismos. Exemplos neste sentido envolvem a constelação da Ema (cultura Tembé - DT1 e LD2): é a maior ave da Amazônia e seu surgimento no céu se dá no período do ano em que há a colheita de alimentos - logo, a região celeste associada à Ema se relaciona a um período de fartura. Já no caso dos Tukano (DT2), a serpente e outros animais peçonhentos se destacam dentre os asterismos. 
Cardoso (2007, p. 157) apresenta algumas reflexões que se relacionam à cultura e ao cotidiano dos Tukano acerca disto: "Aña Diaso [constelação] é uma espécie de Tuchana, isto é, um líder maior entre as serpentes em uma declarada alusão a uma reprodução das relações sociais da tribo.”. Os Tuchaua são líderes indígenas que exercem o papel de representar sua comunidade dentre as demais lideranças locais. Desta forma, indica-se uma possível conexão entre a ordem terrena e a celeste, segundo a ótica Tukano. Em DT3 a ênfase consistiu em explorar a diversidade de olhares na construção das constelações, tendo como exemplo a região identificada com a constelação do Escorpião pela UAI. O trabalho menciona a constelação do anzol (cultura havaiana) e a Ema (cultura Tembé). Os últimos dois materiais que também realizaram discussões nesta temática apresentaram abordagens mais pontuais. CP2 incluiu um texto sobre algumas constelações entre os Tembé (Ema, Seriema, Queixo da Anta). Em CP4, a abordagem às constelações é apenas sugerida a partir da recomendação de uma obra sobre o tema, conferindo caráter opcional à discussão. Além disso, não são dadas justificativas que incentivem o(a) professor(a) a trabalhar com o tema. Como balanço após o detalhamento das abordagens do corpus para esta categoria, ressalta-se a importância de que os materiais destaquem algumas constelações em específico para aprofundar sua abordagem, fazendo uma investigação integrada à cultura e ao cotidiano do grupo e não apenas descrevendo asterismos. Os exemplos retirados de DT2 e DT3 contemplam, de maneira geral, esta necessidade. Outra possibilidade é trazer narrativas que possam se relacionar a algum asterismo, fazendo-se uma posterior discussão sobre as relações existentes com a vida social. Este é o caso de LD2: além da Ema, a constelação do Beija-Flor (Mainamy) também foi associada a aspectos do cotidiano da comunidade.

Os temas abordados nas categorias "Origem do mundo" (OM), "Funcionamento do cosmos" (FC) e "Entes celestes" (EC) se estruturam a partir de narrativas, sendo essa uma característica geral sobre a forma como tais temáticas estão presentes nos materiais. Ressalta-se que os documentos tendem a não fornecer orientações relacionadas a um aprofundamento dessas narrativas. O risco associado a esta carência consiste na redução de tais narrativas a apenas curiosidades sobre culturas que, devido à dificuldade em compreender suas lógicas de pensamento, sejam tomadas como ilógicas ou exóticas, com a conotação negativa que pode assumir este último termo. Em "Origem do mundo" o material que mais se aprofundou no tema (DT3) propôs o trabalho com um texto sobre a origem do mundo, segundo a concepção do povo Desana, indicando-se o trabalho com outros textos relacionados à Bíblia, ao Big Bang e ao Rig Veda em uma articulação entre variadas referências e olhares. Os demais materiais (DT1 e CP1) apenas pontuaram elementos relacionados à temática, indicando materiais ou a solicitação de se realizar pesquisas a respeito deste assunto.

O tema do funcionamento do universo foi a categoria que, junto à abordagem aos asterismos, concentrou maior número de documentos. $\mathrm{O}$ trabalho a ser destacado é P1. O artigo descreve a existência de vários planos cósmicos, segundo os Guarani, que se organizam de forma concêntrica a partir do território em que vivemos. A origem e papéis desempenhados pelo Sol, Lua e estrelas também são apresentados pelo material, além da relação de proximidade entre humanos e entes celestes: para os Guarani, os habitantes da Terra são parentes dos 
objetos do céu. Ressalta-se que em P1 a narrativa sobre o cosmo Guarani aparece de maneira integrada com a necessidade de entender sua forma de pensamento. Os outros materiais que também trataram da temática tiveram abordagens mais pontuais sobre o assunto. Em CP1, as narrativas de funcionamento do cosmo aparecem em uma sugestão de leitura externa, por exemplo. LD1 e LD3 possuem em seus textos-base informações gerais sobre a cosmologia de diversos povos. No primeiro caso, destacam-se os egípcios; no segundo caso, a abordagem é mais ampla e compreende: os sumérios, a China e Grécia Antiga, os incas e os egípcios. É importante frisar que os livros não utilizaram fontes primárias para abordar o tema e que os povos indígenas no Brasil não fizeram parte deste panorama. Apenas em LD1 há uma sugestão de pesquisa sobre a cosmologia Kaiapó.

$\mathrm{Na}$ categoria "Entes celestes" observou-se, em linhas gerais, o mesmo padrão de trabalho das outras temáticas: apresentação de textos com informações e mitos (sobre a Lua, o Sol ou planetas como Vênus), seguidos em alguns casos de uma proposta de atividade (ou debate, como em CP3). Em certa medida, este tipo de formato aborda a diversidade ou pluralidade de pensamento recorrendo apenas à divulgação dos mitos, estando ausente a indicação de um trabalho mais aprofundamento dos conteúdos. As abordagens dadas por DT1 e LD2 possuem similaridades por trabalharem com a mesma cultura de referência, a Tembé. Zahy (Lua) e Zahy-Imiriko (a esposa da Lua) são as personagens das narrativas apresentadas pelos materiais. A atividade em CP3 que se relaciona a esta categoria é "Minisseminários sobre o Sol e a Lua", que previa o uso de dois textos voltados ao tema. O enfoque da pesquisa realizada em DT2 não incluiu um resgate das narrativas relacionadas ao céu, mas ao longo do trabalho o autor apresentou de maneira pontual alguns indícios de mitos voltados a constelações. Como característica recorrente em boa parte das narrativas apresentadas sobre entes celestes, aponta-se uma interação entre figuras relacionadas ao céu, deuses, humanos e animais, havendo em alguns pontos uma indistinção entre eles. Tal característica é marcante na estrutura do pensamento de variadas culturas indígenas.

\subsection{PERSPECTIVAS PARA O MULTICULTURALISMO E A NOÇÃO DE CULTURA NOS DOCUMENTOS}

No que se refere à dimensão de análise 2, cabe destacar uma diferença estrutural em relação à dimensão de análise 1, pois serão utilizadas as categorias propostas por Candau (2008) para o multiculturalismo. Vale ressaltar que a presença das diferentes perspectivas de multiculturalismo não é dada de maneira explícita nos materiais, ficando nas entrelinhas dos discursos os aspectos relacionados à educação, ciência, cultura e sociedade. $\mathrm{O}$ quadro 2 indica a distribuição do corpus tendo em vista as três perspectivas para o multiculturalismo adotadas na análise. 
Quadro 2. Distribuição do corpus de análise de acordo com as categorias para o multiculturalismo

\begin{tabular}{|c|c|c|c|}
\hline Documento & Assimilacionista & Diferencialista & Interculturalidade \\
\hline \multicolumn{4}{|l|}{ DT1 } \\
\hline \multicolumn{4}{|l|}{ DT2 } \\
\hline \multicolumn{4}{|l|}{ DT3 } \\
\hline \multicolumn{4}{|l|}{ P1 } \\
\hline \multicolumn{4}{|l|}{ P2 } \\
\hline \multicolumn{4}{|l|}{ LD1 } \\
\hline \multicolumn{4}{|l|}{ LD2 } \\
\hline \multicolumn{4}{|l|}{ LD3 } \\
\hline \multicolumn{4}{|l|}{$\mathrm{CP} 1$} \\
\hline \multicolumn{4}{|l|}{$\mathrm{CP} 2$} \\
\hline \multicolumn{4}{|l|}{$\mathrm{CP} 3$} \\
\hline CP4 & & & \\
\hline
\end{tabular}

A respeito da categoria do multiculturalismo diferencialista, vale comentar que os documentos produzidos pela Secretaria de Educação de São Paulo (CP1, CP2, CP3, CP4) foram agrupados em uma única categoria, ainda que individualmente possa haver pequenas discrepâncias entre os materiais em termos de inclinações voltadas ao multiculturalismo. Observou-se como aspecto predominante destes materiais a recorrência da menção à diversidade cultural e às criações realizadas por variadas culturas, dando ênfase à ideia de respeito às diferenças e à pluralidade cultural. Estes pontos estão presentes nos documentos a partir de relatos de constelações e outros aspectos da cultura Tembé. É o caso do texto "O céu dos índios Tembé", presente em CP2, e a indicação de leituras como: "As religiões indígenas: o caso tupi-guarani", feita em CP1. Entretanto, estes conteúdos ficam isolados na proposta. Não foi identificada uma discussão perene acerca da noção de que a ciência é um referencial, entre outros, para observar e interpretar o mundo, por exemplo. Sobre a ideia de cultura, não foram localizadas menções e referências a respeito de trocas e intercâmbios.

Os documentos DT1 e DT2 possuem em comum a abordagem de destaque aos saberes de uma dada cultura, Tembé e Tukano, respectivamente. Ambos afirmam que nenhum conhecimento deve ser visto como tendo maior valor epistemológico que os demais; citam também a necessidade de se promover um diálogo intercultural e transcultural. Embora este tipo de menção pudesse direcionar os materiais para a categoria da interculturalidade, foram verificados nas propostas alguns aspectos que não indicaram total coerência com este referencial. Os documentos realizaram comparativos entre os saberes produzidos nas 
culturas indígenas e a astronomia, de forma que os saberes dos povos autóctones são compreendidos a partir da lógica ocidental em alguns momentos. Não se identificou, nesses casos, a consciência das relações de poder no histórico de contato e interação entre os povos, refletidas na existência de uma cultura tomada como referência. É a ausência do questionamento ao referencial privilegiado da cultura ocidental o principal fator para a inclusão destes trabalhos na categoria de multiculturalismo diferencialista. Vale ressaltar que a noção de cultura presente nos elementos DT1 e DT2 não possui viés essencialista. No primeiro caso, o autor enumera situações em que ocorrem trocas culturais entre os Tembé e a sociedade não indígena. Em DT2 também há destaque para este aspecto.

Em relação à categoria interculturalidade, os documentos pertencentes a esse agrupamento (DT3, P1, P2, LD2 e LD3) sustentaram a importância da ideia de diálogo entre saberes de naturezas distintas, sendo estes conhecimentos tomados no mesmo nível de relevância. Dentre os aspectos mais específicos que justificam a inclusão dos documentos nesta categoria, é possível citar a realização de uma crítica à supervalorização da ciência e da noção linear de progresso, que se aproxima da ideia "de que caminhamos sempre para um estágio de desenvolvimento maior e melhor do que o que se tem antes" (COSTA, 2005, p. 100), presente de maneira mais decisiva em DT3 e P2. Neste último caso, o autor afirma que:

Infelizmente vemos muitos desses educadores atuando com inspirações essencialmente teleológicas, [...] onde o fazer científico, da forma em que ele é realizado hoje em dia, é, mais ou menos explicitamente e de forma acrítica, passado como se fosse a maior conquista da espécie humana; como se a abordagem científica tivesse necessariamente um status especial em relação a outras formas de conhecimento. (JAFELICE, 2002, p. 20, grifo nosso).

Ainda em relação a P2, destaca-se que a interculturalidade que o material propõe possui um diferencial, sendo tomada enquanto diálogo entre ciências exatas e humanas, entre saber científico e simbólico. No caso de P1, LD2 e LD3, os aspectos a serem ressaltados dizem respeito ao relativismo cultural, a fim de compreender outras lógicas de pensamento e, consequentemente, afastar-se de etnocentrismos. Como exemplo neste sentido, a temática trabalhada de maneira mais específica em P1, o sistema cosmológico Guarani, possui grande coerência com este propósito. O referencial metodológico adotado no trabalho menciona que é necessário: "relativizar aspectos culturais de nossas origens ou formação cultural e escolar, e a partir desta postura epistemológica, buscar entender a lógica implícita a cada sistema de pensamento, ou cada cultura, na sua totalidade." (MELLO; SOARES; KERBER, 2011, p. 4, grifo nosso). Em LD2 há vários elementos que buscam aproximar a cultura indígena Tembé e a não indígena, trabalhando para o desenvolvimento da empatia entre os diferentes grupos: "Você já parou para pensar? Mirar as estrelas com os olhos dos índios pode ser como achar um novo universo. Juntando mais este pedaço do céu, visto pelos Tembé, será que ele não ficará maior e mais bonito?” (CORRÊE; MAGALHÃES; MASCARENHAS, 1999, p. 10, grifo nosso). Considerando que a linguagem do material visa atingir um público infantojuvenil, a citação anterior 
apresenta a postura de promover a experiência de colocar-se no lugar do outro e experimentar seu ponto de vista, de maneira que tal movimento deva agregar positivamente e ampliar o repertório dos envolvidos. $\mathrm{O}$ trecho também indica uma valorização dos saberes e visão de mundo dos Tembé ao sugerir que o céu ficaria "maior e mais bonito" caso estes sejam considerados.

Sobre a noção de cultura identificada nos materiais, é necessário pontuar que em LD2 o seguinte trecho indica uma desarmonia com o restante da proposta do material: "Aculturados e sofrendo ameaças de perda de grande parte de suas reservas no Pará e Maranhão, os Tembé falam mais o português que o seu dialeto original, mas vêm se esforçando em resgatar sua tradição.” (CORRÊEA; MAGALHÂES; MASCARENHAS, 1999, p. 9, grifo nosso). O termo destacado pode remeter à ideia de que o contato com culturas não indígenas seria um elemento que descaracterizaria a identidade dos Tembé, sendo compatível com uma concepção estática de cultura, em que é necessário se manter "original” ao longo do tempo. Ampliando a discussão sobre a noção de cultura para a categoria interculturalidade como um todo, com exceção ao trecho anterior presente em LD2, o viés predominante dos elementos está próximo a uma noção dinâmica de cultura, devido à menção ao intercâmbio e trocas entre distintos grupos, sendo, portanto, de natureza híbrida e que se constrói a partir do tempo e das relações entre diferentes agentes.

A terceira categoria de análise, o multiculturalismo assimilacionista, foi a menos representativa, possuindo um único elemento, LD1. O principal aspecto que determinou sua identificação com as características deste agrupamento diz respeito à utilização da ciência moderna como matriz de referência para a análise dos feitos de outras sociedades ao longo do tempo. No trecho a seguir fica exemplificada esta ideia geral: "Em certo sentido, os magos e os curandeiros vieram a se tornar os primeiros de uma linhagem de investigadores experimentais, os ancestrais remotos dos cientistas modernos." (PIETROCOLA et al., 2011, p. 22, grifo nosso). As figuras dos magos ou curandeiros estão relacionadas a um mundo simbólico que envolve inúmeros aspectos próprios de uma dada cultura, sendo necessário maior embasamento para afirmar qualquer relação direta destes elementos com o que hoje é identificado com as realizações da ciência. Este olhar se assemelharia a uma postura que busca no outro (e no passado) as realizações que lhes são familiares (no presente), descartando-se a tentativa de compreender o outro de acordo com sua própria lógica de pensamento e sistema de referências. Nesta perspectiva, o olhar apresentado pelo material está centrado no saber científico. Assim, embora se volte à produção cultural de outros povos, estes últimos acabam sendo caracterizados pela falta de elementos ou por uma incompletude, já que são comparados a uma referência que lhes é alheia. É neste sentido que o material apresenta um posicionamento que busca alinhar outras culturas a uma perspectiva hegemônica e que se justifica sua inclusão na categoria do multiculturalismo assimilacionista. Por fim, a concepção de cultura em LD1 acaba sendo compatível com propostas mais lineares e evolucionistas, de maneira que as realizações da cultura ocidental (ciência) são tomadas como parâmetro para se compreender os demais povos. 


\subsection{DISCUSSÃO: INDICANDO PERSPECTIVAS}

Os processos de categorização, envolvendo a elaboração de justificativas e o estabelecimento ou criação das categorias, suscitam a extrapolação e a indicação de novos caminhos a partir da análise. Considerando a dimensão de análise 1 a respeito dos temas abordados em astronomia cultural, é possível afirmar que, entre os materiais que se destinam diretamente à sala de aula (livros didáticos e cadernos da proposta curricular do estado de São Paulo), a abordagem à astronomia cultural teve caráter panorâmico, sem a exploração ou aprofundamento das discussões. Outro aspecto que merece atenção diz respeito a dificuldade de articulação entre os conhecimentos sobre o céu e a cultura, organização social e simbólica das populações não ocidentais mencionadas pelos materiais.

No que diz respeito à forma de abordagem aos temas, embora não tenha sido o enfoque deste âmbito da análise a investigação da maneira como os materiais apresentam seus conteúdos, foi possível identificar que o formato de narrativa surgiu como tendência de estrutura, variando-se o assunto mais específico abordado. Como exceção a esse perfil está a abordagem aos asterismos, com a predominância de um viés descritivo. Chama-se a atenção para o fato de que as narrativas míticas consistem em estruturas complexas e que revelam inúmeros aspectos da racionalidade e visão de mundo dos povos. Sem elementos contextuais ou uma interpretação para seus possíveis significados, a compreensão de tais narrativas não ocorre de forma relevante. A conexão com os conhecimentos do céu, nesse contexto, também se torna frágil.

É possível afirmar também que os temas abordados pelos materiais selecionados apresentaram uma distribuição quantitativa sem grandes desníveis, havendo apenas uma categoria que ficou isolada ("Estações do ano"), com duas abordagens mais pontuais. Outro traço geral do corpus consiste na ênfase de divulgação dos olhares de outras culturas sobre os saberes do céu a partir de textos, sendo pouco frequente o trabalho de se aprofundar ou analisar tais fontes. Em um primeiro momento, a divulgação da multiplicidade de significados atrelados ao céu é necessária, todavia, não deve se esgotar nesta etapa. O estágio seguinte consiste em compreender a lógica de pensamento de outras culturas, ampliando o repertório para além da ciência e da racionalidade ocidental.

Em relação à diversidade de culturas presentes no corpus, este aspecto mostrou-se pouco explorado. Apenas no Brasil, segundo o Censo 2010 realizado pelo Instituto Brasileiro de Geografia e Estatística (IBGE, 2012), a estimativa é a de que haja 305 distintos povos indígenas distribuídos em todo o território. Retornando à tabela 2, verifica-se que apenas nove etnias indígenas foram citadas ou trabalhadas pelo corpus. Um fato que pode explicar a menção a um número restrito de povos é a necessidade de se estabelecer maior comunicação entre as pesquisas realizadas na área de antropologia e o ensino de astronomia cultural. Ou ainda, uma ampla divulgação dos resultados obtidos pelos trabalhos mais recentes na área de pesquisa em astronomia cultural, para que possam chegar até aos materiais didáticos que se destinam ao ensino destes conteúdos.

Em se tratando da dimensão de análise 2, sobre as perspectivas de multiculturalismo e a noção de cultura dos documentos, vale ressaltar que a investigação 
deste eixo busca conectar à astronomia cultural discussões que atualmente são recorrentes nas áreas de humanidades. Do debate sobre as diversas possibilidades de multiculturalismo, defende-se que a proposta que oferece uma visão mais crítica acerca de todos os elementos envolvidos no cenário da sociedade contemporânea é a interculturalidade, sobretudo, pelo questionamento dos referenciais tomados como "naturais" e a adoção de uma perspectiva histórica dos processos relacionados à dinâmica das culturas. $\mathrm{Na}$ análise, esta categoria teve grande representatividade.

Em relação à noção geral de cultura, compreende-se que a interpretação que a concebe como sendo de natureza híbrida (CANCLINI, 2008) e similar a uma teia de significados (GEERTZ, 1989), é a mais compatível com a interculturalidade e interessante como matriz para compreender os fenômenos socioculturais ocorridos mais recentemente. $\mathrm{Na}$ análise, considera-se que, de maneira geral, foram pontuais os trechos com concepções de cultura que precisam passar por críticas mais severas. $\mathrm{O}$ fato de apenas um elemento ser agrupado na categoria do multiculturalismo assimilacionista é um aspecto positivo a ser destacado, pois esta é a concepção que, pelos referenciais adotados, mais precisa ser revista. A ponderação a ser feita é que a maior representatividade da categoria interculturalidade não garantiu que um debate amplo sobre o tema fosse encontrado nos documentos analisados. Além do intercâmbio entre distintos saberes e culturas, pontua-se que esta dimensão de análise também é representativa na defesa de um diálogo mais explícito entre ciências humanas e exatas, elementos estruturantes, inclusive, na constituição da astronomia cultural enquanto área do conhecimento e de pesquisa.

\section{CONSIDERACְÕES FINAIS}

O trabalho realizado explorou algumas das possíveis discussões que envolvem o ensino de astronomia cultural, temática ainda pouco conhecida mesmo por parte dos pesquisadores da área de ensino de ciências da natureza. Devido a este aspecto, torna-se ainda mais necessária a divulgação e discussão dos resultados obtidos por estudos que exploram as potencialidades, dificuldades e limites do ensino desta temática no currículo escolar.

Dentre os aspectos que se destacaram da análise dos materiais e propostas didáticas, encontra-se a ausência de aprofundamento das discussões sobre a cultura e a história das populações abordadas nos conteúdos de astronomia cultural. Esta carência possivelmente se reflete nas abordagens a serem feitas em sala de aula, tendo em vista que, habitualmente, a formação de professores e professoras das áreas de ciências da natureza não contempla discussões relacionadas mais diretamente às ciências humanas. A consequência desta ausência se conecta à superficialidade com que muitas das discussões foram apresentadas pelos materiais. Desta forma, dá-se apenas o primeiro passo, voltado à divulgação das relações entre elementos celestes e socioculturais, sem uma busca por compreendê-las de maneira mais sistemática e integral. Indica-se com isso a necessidade de aprofundamento das abordagens, visando tornar mais analítico, do que descritivo, os textos e propostas em astronomia cultural. Ao invés de apenas apresentar os asterismos existentes em uma dada cultura, buscar compreender seus significados e relações com o cotidiano em seu contexto; no lugar de apenas apresentar narrativas sobre entes 
celestes, atentar para os elementos específicos dos mitos, por exemplo, e como eles se relacionam à identidade do grupo em questão.

A fim de problematizar a carência de aprofundamento no tratamento a alguns temas, considerando a preocupação em abordar os povos originários no território brasileiro, propõe-se a realização de estudos mais amplos e transversais acerca dos povos indígenas no Brasil, necessários de maneira geral às propostas e materiais didáticos na área de ensino de astronomia cultural, enfatizando a atuação dos sujeitos e suas relações com o espaço e ambiente. Independente do grupo étnico considerado, a compreensão das linhas gerais destes aspectos faz-se necessária como elemento que dá maior sustentação a possíveis interpretações que podem ser feitas acerca das relações entre terra e céu no âmbito da astronomia cultural. Ressalta-se ainda a necessidade de diálogo entre pesquisadores de diferentes áreas a fim de se explorar a diversidade étnico-cultural do Brasil, destacando a resistência, permanência e atuação dos povos indígenas na atualidade para ampliar o repertório de fontes e estratégias sobre tópicos de astronomia cultural. Jafelice (2010), ao discutir os aspectos teóricos estruturadores na defesa da astronomia cultural em sala de aula, propõe que o eixo da abordagem não se volte para a astronomia em si (ou quaisquer outras áreas do conhecimento), vista pelo autor apenas como uma "porta de entrada". Isto porque:

O que importa são as pessoas - por serem o que são, além de transformantes/ transformadas do/pelo planeta -, o ambiental - do ponto de vista sistêmico, pelas vidas que abriga e relações simbiônticas gerais que propicia - e os aspectos culturais e sociais envolvidos - pelas representações e significações que permitem que construamos e reconstruamos sem fim. (JAFELICE, 2010, p. 221, grifos do autor)

A compreensão a respeito do modo de vida e lógica de pensamento das populações indígenas, no que diz respeito a sua produção de conhecimento sobre a natureza e sobre os elementos do céu, não apenas coloca em pauta a diversidade cultural nas aulas de ciências da natureza quanto permite discutir aspectos da ciência como construção de uma dada cultura. Tal postura favorece sua compreensão de forma contextualizada, enquanto produto de uma época decorrente das demandas da sociedade ocidental, permitindo o trabalho com a natureza da ciência, ao abordar os processos que a produzem, os objetivos e referenciais que orientam sua construção. Defende-se, assim, a perspectiva elaborada por Aikenhead (2007), em que é falsa a dicotomia entre os "conhecimentos indígenas" e as "ciências eurocêntricas". O autor propõe ainda um projeto no qual são criadas três categorias, que representariam de maneira mais adequada a complexidade deste contexto: "Modos indígenas de viver na natureza" ("Indigenous ways of living in nature"), "Modos neo-indígenas de conhecer a natureza" ("Neo-indigenous ways of knowing nature") e "Ciências eurocêntricas" ("Eurocentric sciences") 4 .

Pierre Clastres (2013) no texto "Copérnico e os selvagens", publicado em "A sociedade contra o Estado", ao discutir o conceito de poder na antropologia política, realiza uma comparação entre a revolução copernicana e as mudanças ocorridas na etnologia a partir do momento em que as chamadas "culturas primitivas" deixaram de "girar em torno" da civilização ocidental. Tomando esta 
ideia de maneira análoga a proposta mais ampla que estrutura a astronomia cultural, indica-se a necessidade de superação da "conversão heliocêntrica", ampliando a afirmação de Clastres (2013, p. 43) de que: "É tempo de buscarmos outro Sol e de nos pormos em movimento". No contexto de atuação deste trabalho, faz-se necessário, antes, criar e vivenciar o tempo de aproximação à cosmologia moderna, em que não há um centro privilegiado para o movimento, em um universo pautado pela diversidade de referenciais, caminhos e olhares para se compreender o céu e, para além dele, a pluralidade da construção do conhecimento sobre a realidade.

\section{REFERÊNCIAS}

AIKENHEAD, G. S. Indigenous Knowledge and science revisited. Cultural Studies of Science Education, v. 2, p. 539-620, 2007.

ALBUQUERQUE, V. et al. Astronomia e cultura nas pesquisas em ensino de ciências na última década. In: SIMPÓSIO NACIONAL DE EDUCAÇÃO EM ASTRONOMIA, 1., 2011. Anais... Disponível em: <http://snea2011.vitis.uspnet.usp.br/sites/default/files/SNEA2011_TCO29. pdf>. Acesso em: 26 ago. 2019.

BARDIN, L. Análise de conteúdo. Lisboa: Editora 70, 2006.

BARROS, O. DOS S. Etnoastronomia Tembé-Tenetehara como matriz de abordagem (etno) matemática no enisno fundamental. 2004. 154 f. Dissertação (Mestrado em Educação em Ciências e Matemática) - Universidade Federal do Pará, Belém, 2004.

BINJA, E. J. B. Multiculturalismo: a identidade do sujeito nas tensões sociais contemporâneas em Charles Taylor. São Paulo, SP: LiberArs, 2015.

BIKLEN, S. K. Investigação qualitativa em educação. Tradução Maria João Alvarez; Telmo Mourinho Baptista. Porto: Porto Editora, 1994. p. 47-51.

BOGDAN, R. C.; BIKLEN, S. K. I. Fundamentos da investigação qualitativa em educação: uma introdução. Capítulo 2: Características da investigação qualitativa. In: BOGDAN, R. C.; BOUTTE, G.; KELLY-JACKSON, C.; JOHNSON, G. L. Culturally Relevant Teaching in Science Classrooms: Addressing Academic Achievement, Cultural Competence, and Critical Consciousness. International Journal of Multicultural Education, v. 12, n. 1, p. 1-20, 2010.

BRASIL. Temas Contemporâneos Transversais na BNCC - Contexto Histórico e Pressupostos Pedagógicos, 2019. Disponível em: <http://basenacionalcomum.mec.gov.br/ images/implementacao/contextualizacao_temas_contemporaneos.pdf >. Acesso em: 23 ago. 2019.

CAMPOS, M. D. A cosmologia dos Caiapós. Scientific American Brasil, n. 14, p. 62-71, fev. 2006.

CANCLINI, N. Introdução à edição de 2001. In: CANCLINI, N. Culturas híbridas: estratégias para entrar e sair da modernidade. Tradução Ana Regina Lessa; Heloísa Pezza Cintrão. São Paulo, SP: Edusp, 2008. p. XVII-XL.

CANDAU, V. M. Multiculturalismo e educação: desafios para a prática pedagógica. In: MOREIRA, A. F.; CANDAU, V. M. (org.). Multiculturalismo: diferenças culturais e práticas pedagógicas. Petrópolis, RJ: Vozes, 2008. p. 13-37. 
CARDOSO, W. T. O céu dos Tukano da Escola Yupuri: construindo um calendário dinâmico. 2007. 390 f. Tese (Doutorado em Educação Matemática) - Pontifícia Universidade Católica de São Paulo, São Paulo, 2007.

CARJUZAA, J. The Positive Impact of Culturally Responsive Pedagogy: Montana's Indian Education for All. International Journal of Multicultural Education, v. 14, n. 3, p. 1-21, 2012.

CORRÊA, I. V.; MAGALHÃES, L.; MASCARENHAS, R. O céu dos índios Tembé. Belém/Pará: Eduepa, 1999.

CLASTRES, P. Copérnico e os selvagens. In: CLASTRES, P. A sociedade contra o estado. Tradução Theo Santiago. São Paulo: Cosac Naify, 2013. p. 25-45.

COSTA, G. B. Uma abordagem humanística para o Ensino de Astronomia no Ensino Médio. 2005, 109 f. Dissertação (Mestrado profissionalizante em Ensino de Ciências e Matemática) Universidade Federal do Rio Grande do Norte, Natal, 2005.

GEERTZ, C. Parte I: Uma Descrição Densa: Por uma Teoria Interpretativa da Cultura. In: GEERTZ, C. A interpretação das culturas. Rio de Janeiro: LTC, 1989. p. 3-21.

GRECO, A. Nascimento da Astronomia. Scientific American Brasil, n. 14, p. 10-14, fev. 2006.

IBGE. Censo 2010: População indígena é de 896,9 mil, tem 305 etnias e fala 247 idiomas, 2012. Disponível em: $\quad<$ https: $/ /$ censo2010.ibge.gov.br/ noticias-censo?busca $=1 \&$ id $=3 \&$ idnoticia $=2194 \& \mathrm{t}=$ censo-2010poblacao-indigena-896-9-mil-tem-305-etnias-fala-274\&view=noticia>. Acesso em: 30 ago. 2019.

INGLIS, C. Multiculturalism: New Policy Respondes to Diversity. United Nations Educational, Scientific and Cultural Organization, Paris, 1996. Disponível em: https://pdfs.semanticscholar. org/533a/7a013bebd79ac76ba99962b98b869e9301d5.pdf. Acesso em: 15 de jan. 2020.

JACOB, M. M.; SABZALIAN, L.; JANSEN, J.; TOBIN, T. J.; VINCENT, C. G.; LaCHANCE, K. M. The Gift of Education: How Indigenous Knowledges Can Trasnsform the Future of Public Education. International Journal of Multicultural Education, v. 20, n.1, p. 1-29, 2018.

JAFELICE, L. C. Nós e o céu: um enfoque antropológico para o ensino de astronomia. In: ENCONTRO DE PESQUISA EM ENSINO DE FÍSICA, 8., 2002. Anais... Disponível em: $<$ http://www.sbf1.sbfisica.org.br/eventos/epef/viii/PDFs/CO19_1.pdf>. Acesso em: 28 ago. 2019.

JAFELICE, L. C. Etnoastronomia: quantos céus existem? Revista Ciência Sempre, n. 12, p. 27-31, 2009.

JAFELICE, L. C. Abordagem Antropológica: educação ambiental e astronômica desde uma perspectiva intercultural. Astronomia, Educação e Cultura. Natal: EDUFRN, Editora da UFRN, 2010, p. 213-262.

KANTOR, C. A. et al. Quanta Física. São Paulo: Editora PD, 2010. v. 2.

LIMA, F. P. et al. Relações céu-terra entre os indígenas no Brasil: distintos céus, diferentes olhares. In: MATSURA, O. T. (org.). História da Astronomia no Brasil. Recife: Cepe, 2013. v. 1, p. 88-130.

LIMA, F. P.; FIGUEIRÔA, S. F. DE M. Etnoastronomia no Brasil: a contribuição de Charles Frederick Hartt e José Vieira Couto de Magalhães. Boletim do Museu Paraense Emílio Goeldi. Ciências Humanas, v. 5, n. 2, p. 295-313, ago. 2010. 
McCARTH, G.; STANTON, C. R. "Let His Voice Be Heard": A community's Response to Inclusion of an Indigenous Counter-Narrative in the District Curriculum. International Journal of Multicultural Education, v. 19, n. 3, p. 1-21, 2017.

MELLO, F. C.; SOARES, J. B.; KERBER, L. DE O. Astronomia e educação intercultural: experiências no ensino de astronomia e ciências em escolas indígenas. In: SIMPÓSIO NACIONAL DE EDUCAÇÃO EM ASTRONOMIA, 1., 2011. Atas... Disponível em: <http://snea2011.vitis. uspnet.usp.br/sites/default/files/SNEA2011_M3_Mello.pdf>. Acesso em: 28 ago. 2019.

MERLUCCI, C. M. D.; KILLNER, G. I.; OLIVEIRA JÚNIOR, J. T. DE. Astronomia cultural nas pesquisas de ensino: um panorama da década atual (2010-2018). In: SIMPÓSIO NACIONAL DE ENSINO DE FÍSICA, 23., 2019. Atas... Disponível em: < https://sec.sbfisica.org.br/eventos/ snef/xxiii/sys/resumos/T0834-1.pdf>. Acesso em: 26 ago. 2019.

OLIVEIRA, E.; LEITE, C. Multiculturalismo na educação básica: uma análise da astronomia cultural nos livros didáticos de física aprovados no PNLD 2018. In: ENCONTRO DE PESQUISA EM ENSINO DE FÍSICA, 17., 2018. Anais... São Paulo: SBF, 2018.

PIETROCOLA, M. et al. Física em contextos: pessoal, social e histórico. Movimento, força e astronomia. São Paulo, SP: FTD, 2011. v. 1.

RODRIGUES, M. S. A diversidade do conhecimento sobre o céu e o ensino de astronomia: propostas didáticas e potencialidades da astronomia cultural. 2015. 185 f. Dissertação (Mestrado em Ensino de Ciências) - Universidade de São Paulo, São Paulo, 2015.

RODRIGUES, M. S.; LEITE, C. "Astronomia cultural" em livros didáticos de física aprovados no PNLEM 2012. In: SIMPÓSIO NACIONAL DE EDUCAÇÃO EM ASTRONOMIA, 2., 2012. Atas... Disponível em: < https://www.sab-astro.org.br/wp-content/uploads/2017/03/ SNEA2012_TCO17.pdf>. Acesso em: 30 mar. 2020.

RODRIGUES, M. S.; LEITE, C. O tema astronomia cultural nos referenciais curriculares estaduais no Brasil. In: ENCONTRO NACIONAL DE PESQUISA EM EDUCAÇÃO EM CIÊNCIAS, 10., 2015. Atas... Disponível em: < http://www.abrapecnet.org.br/enpec/x-enpec/anais2015/ resumos/R2117-1.PDF>. Acesso em: 30 mar. 2020.

SANTOS, M. Introdução geral. In: SANTOS, M. Por uma outra globalização - Do pensamento crítico à consciência universal. $6^{\mathrm{a}}$ ed. Rio de Janeiro: Editora Record, 2001. p. 17-21.

SÃO PAUlO (ESTADO). Caderno do Professor: ciências, ensino fundamental - $5^{\text {a }}$ série. São Paulo: SEE, 2009a. v. 4.

SÃO PAUlO (ESTADO). Caderno do Professor: ciências, ensino fundamental - $\sigma^{a}$ série. São Paulo: SEE, 2009b. v. 1.

SÃO PAUlO (ESTADO). Caderno do Professor: ciências, ensino fundamental $-7^{\text {a }}$ série. São Paulo, SP: SEE, 2009c. v. 3.

SÃO PAULO (ESTADO). Caderno do Professor: física, ensino médio - $1^{\text {a }}$ série. São Paulo, SP: SEE, 2009d. v. 3.

UNESCO. Declaração Universal sobre a Diversidade Cultural, 2001. Disponível em: $<$ http:// www.unesco.org/new/fileadmin/MULTIMEDIA/HQ/CLT/diversity/pdf/declaration_cultural_ diversity_pt.pdf $>$. Acesso em: 23 ago. 2019. 


\section{NOTAS}

1 Em Rodrigues (2015) consta maior detalhamento da análise de materiais didáticos, incluindo discussões e reflexões mais amplas a respeito do contexto geral da diversidade cultural no ensino de ciências da natureza.

2 O Journal of Astronomy in Culture, destinado à pesquisa em astronomia cultural, também consiste em uma fonte relevante, entretanto, a preocupação com aspectos da aprendizagem e ensino da astronomia cultural não está garantida, a priori, em suas publicações.

3 Em termos da seleção dos trechos analisados nos documentos, foram considerados apenas os textos-base, excluindo-se um olhar específico a eventuais ilustrações. No caso de exercícios ou questões, considerou-se apenas os temas abordados.

4 Tradução para o português das categorias de Aikenhead (2007) realizada pelas autoras.

Submetido em 11/10/2019

Aprovado em 19/02/2020

\section{Contato:}

Rua do Matão, n.1371 - Butantã

Prédio principal do IFUSP - Ala II - Sala 3010

CEP 05.508-090 - São Paulo, SP - Brasil 